\title{
An Experimental Study on Treatment of Typical Low and Intermediate Level Radioactive Wastes with Thermal Plasma Melting Technology
}

\author{
Wenzhang Xie, Peng Lin*, Jie Lu, Xiajie Liu, Mingzhou Chen, Yonghong Lv \\ Environment Engineering Center, China Nuclear Power Technology Research Institute, Shenzhen, China
}

Email address:

lin_peng@cgnpc.com.cn (Peng Lin)

${ }^{*}$ Corresponding author

To cite this article:

Wenzhang Xie, Peng Lin, Jie Lu, Xiajie Liu, Mingzhou Chen, Yonghong Lv. An Experimental Study on Treatment of Typical Low and Intermediate Level Radioactive Wastes with Thermal Plasma Melting Technology. International Journal of Materials Science and Applications. Vol. 7, No. 4, 2018, pp. 147-152. doi: 10.11648/j.ijmsa.20180704.15

Received: June 3, 2018; Accepted: July 19, 2018; Published: August 21, 2018

\begin{abstract}
With the active development of the nuclear industry in China, it is extremely urgent to study and develop advanced technologies for the radioactive waste treatment and disposal. With features of high temperature, high energy density and broad applicability, the thermal plasma melting technology has been considered as one of the key subjects in the radioactive waste treatment research field. A pilot scale experimental study was carried out on the treatment of typical low and intermediate level radioactive wastes (LILWs) from the nuclear power plant in China with thermal plasma melting technology. Two representative wastes, thermal insulation waste and cotton, were selected and melted in the plasma melting furnance at $1250^{\circ} \mathrm{C}$ for $\sim 100$ minutes until they were completely vitrified. Meanwhile, tracers of $\mathrm{Co}_{2} \mathrm{O}_{3}, \mathrm{CsCl}$ and $\mathrm{SrCO}_{3}$ were added to the original wastes to simulate the containment effect of ${ }^{58} \mathrm{Co}$ and ${ }^{60} \mathrm{Co},{ }^{134} \mathrm{Cs}$ and ${ }^{137} \mathrm{Cs}$ as well as ${ }^{90} \mathrm{Sr}$ in the vitrification during the treatment process. The XRD patterns of both vitrification samples displayed as the typical amorphous state. Performances of resultant glass waste-forms, including the physical property, the leachability and the mechanical capacity, were in accordance with the standard requirements of the hign level radioactive waste glass vitrificaton, and were better than those of the cement solidified waste. Further experimental work is in need to better understand the radioactive nuclide migration regularity and to improve the performance of the plasma melting system.
\end{abstract}

Keywords: LILW, Thermal Plasma, Glass Vitrification

\section{Introduction}

The utilization of nuclear energy can reduce the consumption of traditional fossil energy and the emission of carbon and pollutes. As a result, the nuclear energy has been widely acknowledged as a clean energy. With the active development of the nuclear industry in China, the volume reduction treatment and the final safe disposal of radioactive wastes from nuclear power plants have become crucial problems which are of intense concern by general public. Therefore, it is extremely urgent to study and develop advanced technologies for the radioactive waste treatment and disposal.

With features of high temperature, high energy density and broad applicability, the thermal plasma melting technology has been applied in the treament of hazardous waste such as incineration ash, medical garbage and printed circuit board (PCB). Now it is considered as one of the key subjects in the radioactive waste treatment research field [1]. According to relevant studies in the USA, Japan, Korea and Taiwan area, high volume reduction factors as well as stable waste forms containing radioactive nuclides can be obtained with the thermal plasma treatment technology [2-5]. Recently, a pilot scale plasma melting system for the radioactive waste treatment was established in CNPRI and several experimental studies were performed on the system [6-10].

In present work, two types of typical low and intermediate level radioactive wastes (LILWs) from the nuclear power 
plant in China were chosen to be experiment materials. Parameters indicating the operation status of the thermal plasma melting system together with performance parameters of the glass vitrifications were recorded and analyzed to estimate the applicability of the system in the radioactive waste treatment field.

\section{Materials and Methods}

\subsection{Materials}

As shown in Figure 1, two types of uncontaminated typical LILWs from the nuclear power plant in China, i.e. thermal insulation waste and cotton, were selected to be the simulated radioactive wastes. Compositions of the simulated wastes were listed in Table 1. The thermal insulation waste was pre-treated into flocs with the dimension of $\sim 10 \mathrm{~cm}$. The cotton was firstly converted into ash after complete combustion in the muffle furnace; then the ash were treated with the compression granulation technology, resulting in particles with diameters between $15 \sim 20 \mathrm{~mm}$. In order to eliminate the moisture effect, the materials were placed in the constant temperature drying oven for at least $1 \mathrm{~h}$ at the temperature of $105^{\circ} \mathrm{C}$ before the experiment.

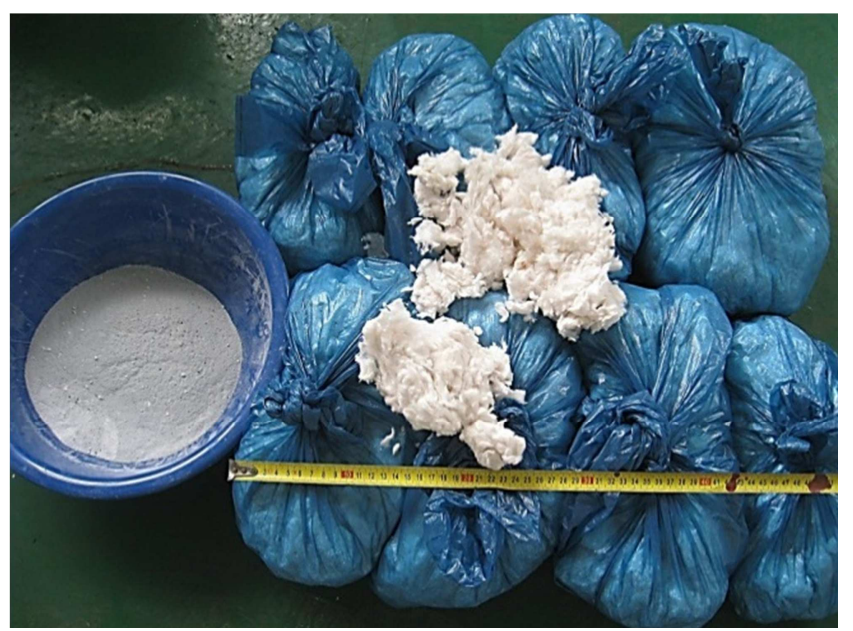

(a)

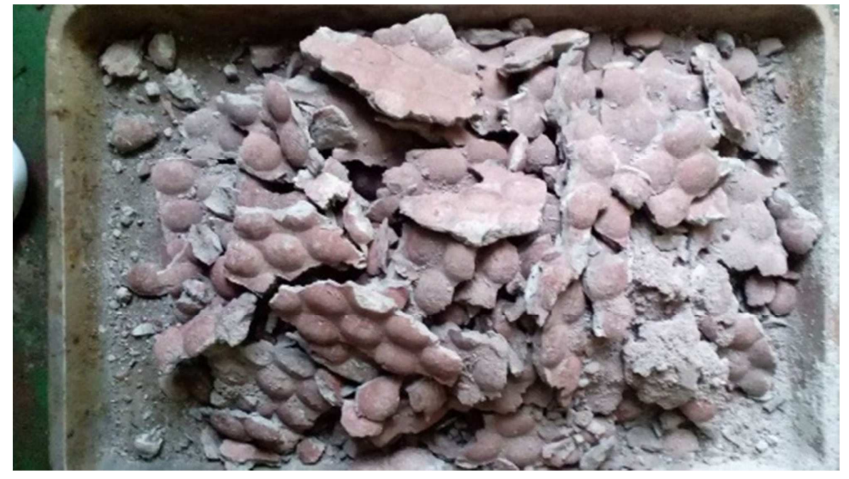

(b)

Figure 1. Simulated radioactive wastes: (a) thermal insulation waste; (b) incineration ash of cotton.
Table 1. Compositions of two typical radioactive wastes from the nuclear power plant in China.

\begin{tabular}{lll}
\hline $\begin{array}{l}\text { Composition (mass } \\
\text { fraction \%) }\end{array}$ & Wastes & Thermal insulation \\
\cline { 2 - 3 } & waste (BX) & $\begin{array}{l}\text { Incineration ash of } \\
\text { cotton (MZ) }\end{array}$ \\
\hline $\mathrm{SiO}_{2}$ & 71.7 & 14.9 \\
$\mathrm{~B}_{2} \mathrm{O}_{3}$ & 2.27 & 4.07 \\
$\mathrm{Na}_{2} \mathrm{O}$ & 15.7 & 1.01 \\
$\mathrm{CaO}$ & 7.88 & 74.6 \\
$\mathrm{MgO}$ & 2.00 & - \\
$\mathrm{CuO}$ & - & - \\
$\mathrm{TiO}$ & - & - \\
$\mathrm{ZnO}$ & - & - \\
$\mathrm{Fe}_{2} \mathrm{O}_{3}$ & 0.486 & 3.01 \\
$\mathrm{Al}_{2} \mathrm{O}_{3}$ & - & 2.38 \\
\hline
\end{tabular}

In line with previous research experiences of the glass vitrification formula, the borosilicate glass was chosen to be the base and a few additives were added according to the original compositions of the simulated wastes [10], including boric acid $\left(\mathrm{H}_{3} \mathrm{BO}_{3}\right)$, sodium carbonate $\left(\mathrm{Na}_{2} \mathrm{CO}_{3}\right)$ and silicon dioxide $\left(\mathrm{SiO}_{2}\right)$. Radioactive nuclides of ${ }^{58} \mathrm{Co},{ }^{60} \mathrm{Co},{ }^{134} \mathrm{Cs}$, ${ }^{137} \mathrm{Cs}$ and ${ }^{90} \mathrm{Sr}$ were common nuclides in concern during the reactor operation and maintenance period. Therefore, nonradioactive isotopes of $\mathrm{Co}, \mathrm{Cs}$, and $\mathrm{Sr}$ were chosen to be indicators of corresponding nuclides in this study. The additive amount of each isotope tracer, in compound forms of $\mathrm{Co}_{2} \mathrm{O}_{3}, \mathrm{CsCl}$ and $\mathrm{SrCO}_{3}$, was around $0.2 \mathrm{wt} \%$ of the total materials in the glass formula to avoid influence on the glass property. The modified glass formula and tracer information were shown in Table 2.

Table 2. Content of the glass formula and tracers [10].

\begin{tabular}{llll}
\hline & & \multicolumn{2}{l}{ Wastes } \\
\cline { 3 - 4 } & & $\mathbf{B X}$ & $\mathbf{M Z}$ \\
\hline & $\mathrm{Original} \mathrm{wastes}$ & 77 & 45 \\
Glass formula (mass & $\mathrm{H}_{3} \mathrm{BO}_{3}$ & 23 & 12 \\
fraction \%) & $\mathrm{Na}_{2} \mathrm{CO}_{3}$ & - & 15 \\
& $\mathrm{Al}_{2} \mathrm{O}_{3}$ & - & - \\
& $\mathrm{SiO}_{2}$ & - & 28 \\
& $\mathrm{Co}_{2} \mathrm{O}_{3}$ & 0.212 & 0.195 \\
Tracer (mass fraction\%) & $\mathrm{SrCO}_{3}$ & 0.232 & 0.221 \\
& $\mathrm{CsCl}$ & 0.224 & 0.194 \\
\hline
\end{tabular}

\subsection{The Plasma Melting System}

Figure 2 shows the schematic figure of the plasma melting system. It consists of the gasification and melting furnace, the secondary combustion chamber, the off-gas treatment system and control system. There are three non-transferred type arc plasma generators, each with a rated power of $120 \mathrm{~kW}$, in the gasification and melting furnace. After fed into the gasification and melting furnace, the mixed materials are gasified at high temperature and the residual ash part of the product is solidified into the glass vitrification. The gas part of the product enters the secondary combustion chamber for complete combustion. Then the off-gas leaves the secondary combustion chamber and goes into the off-gas treatment system, which purifies the off-gas with quencher, baghouse filter, activated charcoal adsorbent bed, scrubbing tower and 
selective catalytic reduction (SCR) system in sequence. In the end, the purified off-gas is released into the air through the stack of the ventilation system.

The treatment capacity is designed as $50 \mathrm{~kg} / \mathrm{h}$. This system can be utilized in the treatment of technical and process wastes including exposure suit, rag, plastic, metal, thermal insulation material, filter cartridge and resin, etc..

\subsection{Experienced Method}

All the materials were mixed based on the ratios listed in Table 2 and fully stirred until they were uniformly mixed. Then the materials were divided into small packages with the same weight of $5 \mathrm{~kg}$, so that they could be fed into the furnace in batches in the experiment.

The plasma melting system must be inspected, cleaned and tested before formal startup. When the system was in stable operation state and the temperature of the gasification and melting furnace stay around $1250^{\circ} \mathrm{C}$, materials were fed into the furnace package by package; at the same time, the feeding time and temperature were recorded. A new package of materials should not be fed until the former one was completely disposed and the temperature returned to the original level before feeding. This operation repeated till all the packages of the present batch were fed and disposed completely. After that, the generator was shut down and the discharge passage on the bottom of the furnace was opened. The outflow of molten glass was collected in a sample container and then cooled down to the state of glass vitrification at room temperature. Finally, sample analysis were conducted on the vitrification samples. Since there was no organic wastes in the original experiment materials, monitoring of parameters relating to the gas pollution was not in consideration in this experiment.

\section{Results and Discussion}

\subsection{Melting Temperature and Time Duration}

The power of the plasma generator, the operation temperature of the melting furnace and the melting time duration of the simulated wastes were recorded during the experiment.

As shown in Figure 3, the power of the plasma generator reached the pre-set value of $115 \mathrm{~kW}$ within 10 min and then remained in the stable operation state to heat the melting furnace. The temperature of the melting furnace rose from the room temperature to the working temperature of $1250^{\circ} \mathrm{C}$ in about $3 \mathrm{~h}$ (see Figure 4). Then materials were fed into the furnace package by package. After approximately $100 \mathrm{~min}$, all packages of materials were fed, melted and converted into the state of molten glass. It then flowed out through the discharge passage to a sample container and cooled down in the air.

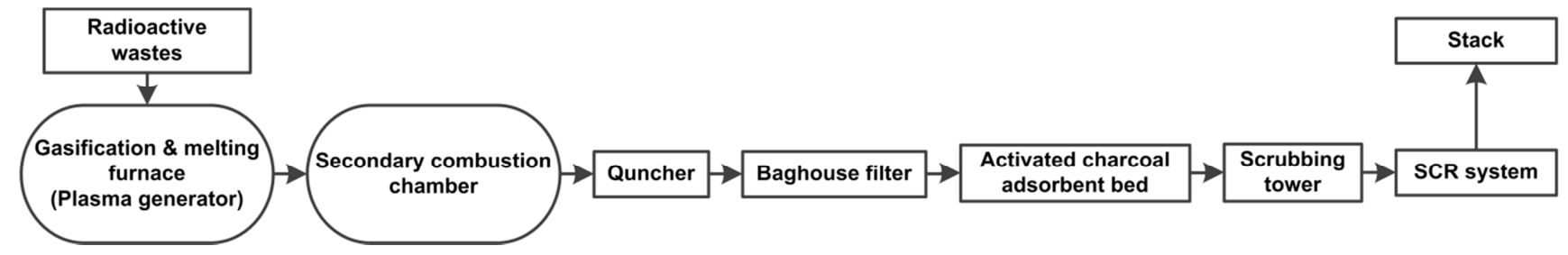

Figure 2. Schematic figure of the plasma melting system.

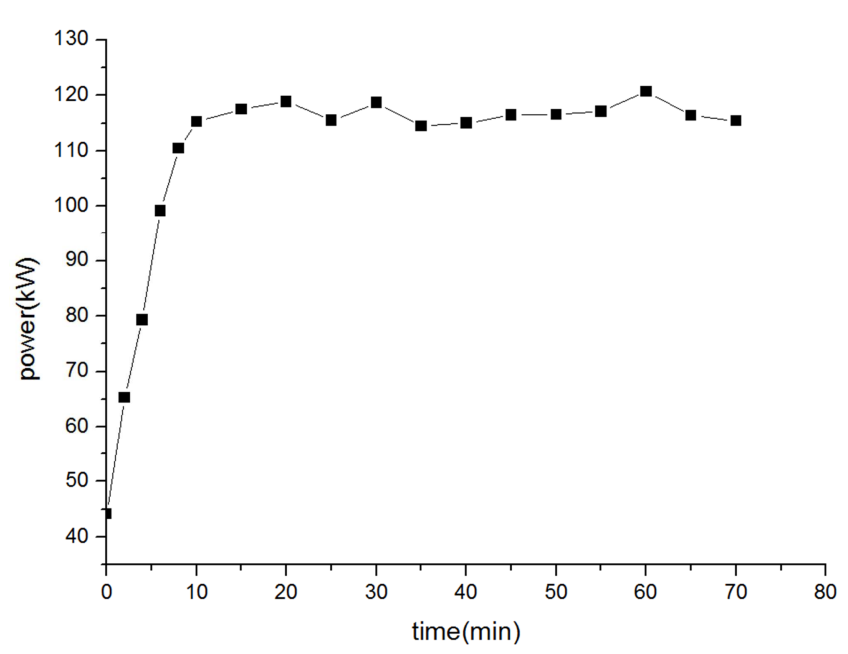

Figure 3. Relationship curve between the power of plasma torch and the operation time.

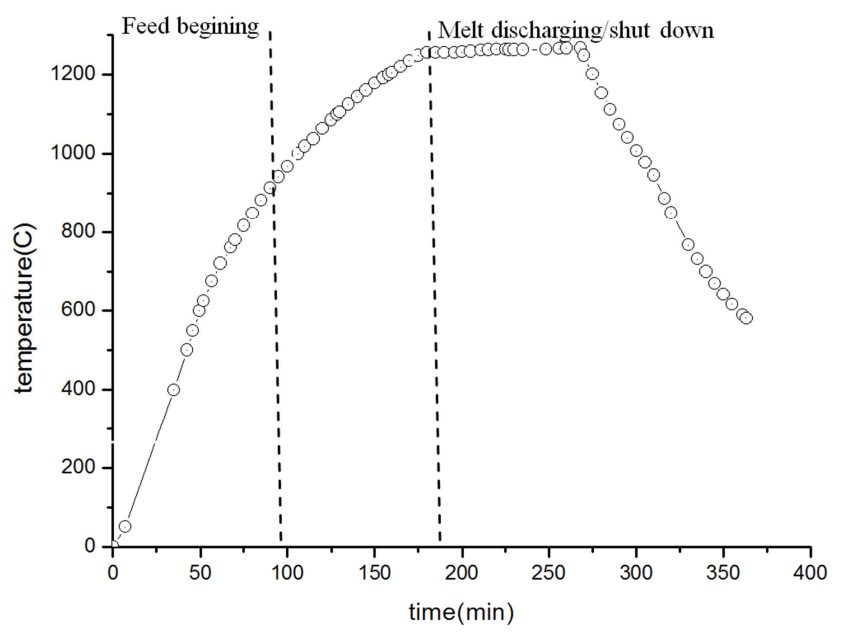

Figure 4. Relationship curve between the temperature of melting furnace and the operation time. 3.2. Glass Vitrification

\subsubsection{XRD Analysis}

Vitrifications of the two simulated wastes in this study are given in Figure 5 and a typical XRD pattern is given in Figure 
6. From the appearance shown in Figure 5, both of the vitrifications are in the glassy form. In Figure 6, the vertical coordinate is the relative intensity and the horizontal is the diffraction angle. The diffraction peak of the vitrification appears to be the typical amorphous state, which indicates that the vitrification is in complete glassy state.

\subsubsection{Vitrification Performance Analysis}

Due to the fact that there is no standard relating to glass vitrifications of LILWs in China, performance indicators of vitrifications in current study were determined as follows referring to similar studies [11-12]:

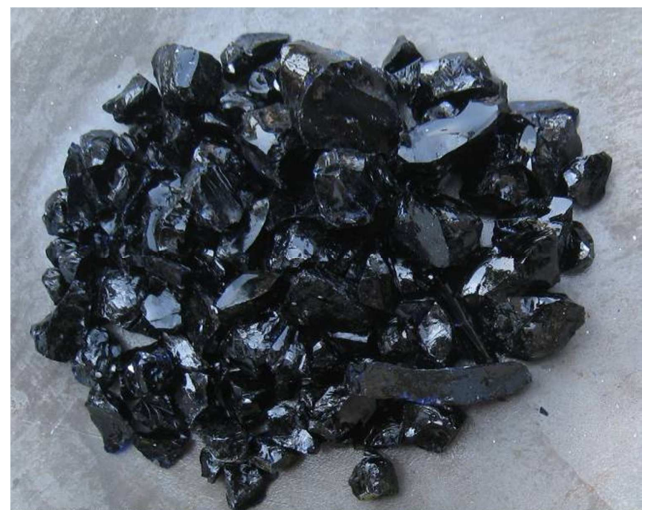

(a)

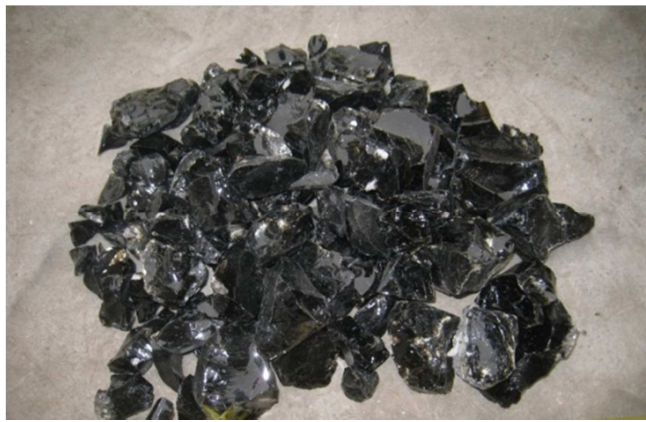

(b)

Figure 5. Glass vitrifications of: (a) thermal insulation waste and (b) cotton.

i. Density: $\geq 2.5 \mathrm{~g} / \mathrm{cm}^{3}$, with reference to the glass vitrification of high level radioactive waste;

ii. Leachability: Under the condition of a 28-day static immersion in the deionized water of $90^{\circ} \mathrm{C}$, the total weight loss per surface area should be $\leq 15.0 \mathrm{~g} / \mathrm{m}^{2}$, and the normalized leaching rates of element $\mathrm{Si}, \mathrm{B}, \mathrm{Na}, \mathrm{Cs}$ and $\mathrm{U}$ should be $<1 \mathrm{~g} /\left(\mathrm{m}^{2} \cdot \mathrm{d}\right)$;

iii. Compressive strength: $\geq 7 \mathrm{MPa}$, better than the cement solidified waste;

iv. Shock resistance: $\leq 12 \mathrm{~cm}^{2} / \mathrm{J}$, with reference to the glass vitrification of high level radioactive waste.

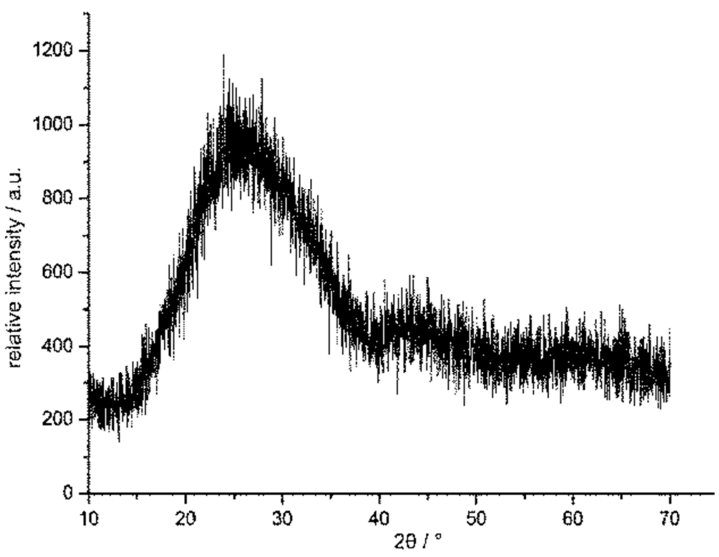

Figure 6. A typical XRD pattern of the glass vitrification.

The static coal sampling method described in reference GB/T 475-2008 was applied to the sampling of cooled glass vitrification [13]. With the cross principle, four groups of vitrification samples were collected respectively from the center of each quadrant. The density was measured with the buoyancy method in reference GB/T 5432-2008 [14], while the normalized element leaching rate with the static leaching test in ASTM C 1220 [15] and the shock resistance with the heavy free fall shock test in EJ 1186-2005. The compressive strength was tested according to the reference GB/T 8489-2006 [16].

Performance parameters of the two vitrifications of the two simulated wastes in this study are summarized in Table 3 and Table 4. From these results, both of the vitrifications meet the disposal requirements for physical property, leachability and mechanical capacity regulated in the reference EJ 1186-2005. From Table 4, normalized leaching rates of tracing istopes of $\mathrm{Co}$, Cs and $\mathrm{Sr}$ are all under $1 \mathrm{~g} /\left(\mathrm{m}^{2} \cdot \mathrm{d}\right)$, however, a large part of the results of $\mathrm{Cs}$ and $\mathrm{Sr}$ is below the detection limit. There might be two reasons for this: on one hand, the vitrifications possess relatively good performance of leaching resistance; on the other hand, tracing isotopes volatilize under the condition of high temperature, leading to the poor containment of nuclides within the vitrification. Further experimental study on nuclide migration and distribution regularity in the plasma melting system need to be carried out for explanation and validation, including element analysis of the vitrification and nuclide retaining efficiency test, etc.

Table 3. Physical properties of the glass vitrification.

\begin{tabular}{|c|c|c|c|c|c|}
\hline Waste & Sample & Density $\left(\mathrm{g} / \mathrm{cm}^{3}\right)$ & Weight loss $\left(\mathrm{g} / \mathrm{m}^{2}\right)$ & Compressive strength (MPa) & Shock resistance $\left(\mathrm{cm}^{2} / J\right)$ \\
\hline \multirow{6}{*}{$\mathrm{BX}$} & $1 \#$ & 2.52 & 4.8 & 74 & 8.5 \\
\hline & $2 \#$ & 2.62 & 3.5 & 95 & 7.9 \\
\hline & $3 \#$ & 2.52 & 4.7 & 78 & 7.9 \\
\hline & $4 \#$ & 2.54 & 3.8 & 81 & 8.2 \\
\hline & Mean value & 2.55 & 4.2 & 82 & 8.125 \\
\hline & Standard deviation & $4.76 \mathrm{E}-02$ & 0.65 & 9.1 & 0.29 \\
\hline $\mathrm{MZ}$ & $1 \#$ & 2.82 & 5.9 & 136 & 9.2 \\
\hline
\end{tabular}




\begin{tabular}{|c|c|c|c|c|c|}
\hline Waste & Sample & Density $\left(\mathrm{g} / \mathrm{cm}^{3}\right)$ & Weight loss $\left(\mathrm{g} / \mathrm{m}^{2}\right)$ & Compressive strength (MPa) & Shock resistance $\left(\mathrm{cm}^{2} / J\right)$ \\
\hline & $3 \#$ & 2.61 & 6.8 & 129 & 9.6 \\
\hline & $4 \#$ & 2.69 & 6.8 & 124 & 10.7 \\
\hline & Mean value & 2.68 & 6.65 & 128 & 9.975 \\
\hline & Standard deviation & 0.102 & 0.52 & 5.94 & 0.69 \\
\hline
\end{tabular}

Table 4. Leaching performance of the glass vitrification.

\begin{tabular}{|c|c|c|c|c|c|c|c|}
\hline \multirow{2}{*}{ Waste } & \multirow{2}{*}{ Sample } & \multicolumn{6}{|c|}{ Normalized leaching rate $\left(\mathrm{g} /\left(\mathrm{m}^{2} \cdot \mathrm{d}\right)\right)$} \\
\hline & & $\mathbf{S i}$ & B & $\mathbf{N a}$ & Cs & Co & $\mathrm{Sr}$ \\
\hline \multirow{6}{*}{$\mathrm{BX}$} & $1 \#$ & 0.362 & 0.497 & 0.008 & - & 0.355 & - \\
\hline & $2 \#$ & 0.258 & 0.372 & 0.006 & - & 0.257 & - \\
\hline & $3 \#$ & 0.359 & 0.516 & 0.008 & - & 0.332 & - \\
\hline & $4 \#$ & 0.277 & 0.399 & 0.006 & - & 0.272 & - \\
\hline & Mean value & 0.314 & 0.446 & 0.007 & - & 0.304 & - \\
\hline & Standard deviation & $5.426 \mathrm{E}-02$ & $7.115 \mathrm{E}-02$ & $1.155 \mathrm{E}-03$ & - & 4.697E-02 & - \\
\hline \multirow{6}{*}{$\mathrm{MZ}$} & $1 \#$ & 0.259 & 0.353 & 0.409 & - & 0.004 & 0.608 \\
\hline & $2 \#$ & 0.324 & 0.447 & 0.496 & - & 0.006 & 0.726 \\
\hline & $3 \#$ & 0.301 & 0.424 & 0.471 & - & 0.005 & 0.693 \\
\hline & $4 \#$ & 0.308 & 0.412 & 0.468 & - & 0.005 & 0.685 \\
\hline & Mean value & 0.298 & 0.409 & 0.461 & - & 0.005 & 0.678 \\
\hline & Standard deviation & $2.772 \mathrm{E}-02$ & $4.006 \mathrm{E}-02$ & $3.687 \mathrm{E}-02$ & - & $8.165 \mathrm{E}-04$ & 4.993E-02 \\
\hline
\end{tabular}

Note: “-" for undetected

\section{Conclusion}

A preliminary experiment was conducted on the pilot scale plasma melting system for radioactive waste treatment. Two types of typical LILWs from the nuclear power plant in China, i.e. thermal insulation waste and cotton, were selected to be the experimental materials. The following conclusions can be derived from the experiment results:

i. The borosilicate glass can work as the basic glass formula for both type of simulated radioactive wastes in this study. The wastes can be completely solidified into the corresponding glass vitrifications under the condition of being melted for 100 min at the temperature of $1250^{\circ} \mathrm{C}$;

ii. For both kinds of glass vitrifications, the densities were larger than $2.5 \mathrm{~g} / \mathrm{cm}^{3}$, the total weight losses in leaching tests were lower than $7 \mathrm{~g} / \mathrm{m}^{2}$, the compressive strengths were greater than $80 \mathrm{MPa}$ and the shock resistances were less than $10 \mathrm{~cm}^{2} / \mathrm{J}$. In a word, performances of both kinds of glass vitrifications were compatible with the requirement of the hign level radioactive waste glass vitrificaton, and were better than those of the cement solidified waste.

Further study will be carried out on the radioactive nuclide migration and distribution regularity in the plasma melting system. Process parameters of the system will be optimized to increase the applicability of the thermal plasma melting technology in the area of radioactive waste treatment.

\section{References}

[1] International Atomic Energy Agency. Application of thermal technologies for processing of radioactive waste. Vienna, 2006.

[2] Womack R. K., Shuey M. W. Development and Use of the Dualmode Plasma Torch. Tucson, Arizona, USA: Proceedings of the Waste Management Conference. 2002, pp. 200-208.
[3] Nakashima M., Fukui T., Nakashima N., et al. Characterization of Solidified Products Yielded by Plasma Melting Treatment of Simulated Non-metallic radioactive waste. Journal of Nuclear Science and Technology. Vol. 39, No. 6, 2002, pp. 687-694.

[4] Park J. K., Song M. J. Feasibility Study on Vitrification of Intermediate and Low Level Radioactive Waste from Pressurized Water Reactors. Waste Management. Vol. 18, No. 3, 1998, pp. 157-167.

[5] Tzeng C. C., Kuo Y. Y., Huang T. F., et al. Treatment of Radioactive Waste by Plasma Incineration and Vitrification for Final Disposal. Journal of Hazardous Materials. Vol. 58, No. 1/3, 1998, pp. 207-220.

[6] Xu W. B., Lv Y. H., Chen M. Z., etc.. Experimental study on simulated radioactive wastes vitrification with arc plasma. Nuclear Power Engineering. Vol. 36, No. 6, 2015, pp. 175-179.

[7] Chen M. Z., Bai B., Liu X. J., etc.. Development of glass formulation for plasma vitrification of combustible solid wastes from nuclear power plants. Radiation Protection. Vol. 35, No. 5, 2015, pp. 262-266.

[8] Chen M. Z., Huang W. Y., Lv Y. H., etc.. Numerical simulation and experiment of plasma torch for LILW vitrification. Nuclear Fusion and Plasma Physics. Vol. 36, No. 3, 2016, pp. 282-288.

[9] Lin P., Lu J., Liu X. J., etc.. Investigation of thermal plasma melting of typical intermediate and low level radioactive wastes from nuclear power plant. Materials China. Vol. 35, No. 7, 2016, pp. 504-508.

[10] Lin P., Qin Y. X., Lv Y. H., et al. Temperature Simulation of Thermal Plasma Melting Furnace for Disposal of Radioactive Waste and Preliminary Research of Vitrification Formula. Radiation Protection. Vol. 33, No. 4, 2013, pp. 206-211.

[11] Commission on Science, Technology and Industry for National Defense. EJ 1186-2005, Characterization of Radioactive Waste Forms and Packages. Beijing: China Environmental Science Press, 2005-04-11. 
[12] Ministry of Environment Protection, General Administration of Quality Supervision, Inspection and Quarantine of the People's Republic of China. GB 14569.1-2011, Performance Requirements for Intermediate and Low Level Radioactive Waste Form - Cemented Waste Form. Beijing: China Environmental Science Press, 2011-09-01.

[13] Standardization Administration of the People's Republic of China. GB/T 475-2008, Method for Manual Sampling of Commercial Coal. Beijing: Standards Press of China, 2009-05-01.

[14] Standardization Administration of the People's Republic of China. GB/T 5432-2008, Test Method for Density of Glass by Buoyancy. Beijing: Standards Press of China, 2009-04-01.
[15] ASTM International. ASTM C1220-17, Standard Test Method for Static Leaching of Monolithic Waste Forms for Disposal of Radioactive Waste. West Conshohocken, PA, 2017, www.astm.org.

[16] Standardization Administration of the People's Republic of China. Test Method for Compressive Strength of Fine Ceramics (Advanced Ceramics, Advanced technical ceramics), GB/T 8489-2006. Beijing: Standards Press of China, 2006-09-01. 